\title{
PENGARUH LINGKUNGAN KERJA TERHADAP KINERJA PEGAWAI PADA BADAN PENYELENGGARA JAMINAN SOSIAL KETENAGAKERJAAN JAWA BARAT
}

\section{Syifa' Pri Widyastuti, Dian Indiyati}

Universitas Telkom Bandung Jawa Barat, Indonesia

Email: priwidyastuti@gmail.com,dianindiyati@telkomuniversity.ac.id

\begin{abstract}
Abstrak
Sektor publik kini bertrasnformasi menjadi orientasi terhadap pelayanan. Sehingga, kinerja menjadi salah satu tolak ukur keberhasilan. Kualitas perusahaan dapat tercermin dari hasil kinerja yang diperoleh. Tujuan yang ingin dicapai dari penelitian ini adalah untuk mengetahui pengaruh lingkungan kerja secara fisik dan non fisik terhadap kinerja pegawai pada BPJS Ketenagakerjaan Bandung Lodaya Jawa Barat. Penelitian ini mempergunakan metode penelitian kuantitatif deskriptif dengan metode analisis data yaitu analisis jalur dan pengambilan data populasi melalui survey kepada 36 pegawai. Hasil penelitian menunjukan lingkungan kerja fisik dan non fisik berpengaruh secara simultan dan parsial terhadap kinerja pegawai. Hasil perhitungan analisis jalur lingkungan kerja fisik memiliki total pengaruh sebesar 55\% sementara lingkungan kerja non fisik sebesar 29,7\% terhadap kinerja pegawai. Sehingga dapat disimpulkan bahwa untuk meningkatkan kinerja pegawai dapat diperbaiki melalui lingkungan kerja.
\end{abstract}

Kata Kunci: lingkungan kerja; kinerja pegawai; analisis jalur

\section{Abstract}

The public sector is now transforming into service orientation. Thus, performance becomes one of the benchmarks of success. The quality of the company can be reflected in the results of the performance. This research aimed to know the influence of the physical and non-physical work environment on the performance of employees at BPJS Ketenagakerjaan Bandung Lodaya West Java. This study used descriptive quantitative method with path analysis and population data retrieval through survey of 36 employees. The results showed that the physical and nonphysical work environment had a simultaneous and partial effect on employee performance. The results of the calculation of physical work environment path analysis has a total influence of 55\% while the non-physical work environment of $29.7 \%$ on employee performance. Therefore, to improve employee performance can be improved through the work environment.

Keywords: employee performance; work environment; path analysis

\begin{tabular}{ll}
\hline How to cite: & Widyastuti, Syifa' Pri. Dian Indiyati (2021) Pengaruh Lingkungan Kerja terhadap Kinerja Pegawai \\
& $\begin{array}{l}\text { pada Badan Penyelenggara Jaminan Sosial Ketenagakerjaan Jawa Barat. Syntax Literate: Jurnal Ilmiah } \\
\text { Indonesia. 6(7). http://dx.doi.org/10.36418/ syntax-literate.v6i7.3467 }\end{array}$ \\
& 2548-1398 \\
E-ISSN: & Ridwan Institute \\
Published by: &
\end{tabular}




\section{Pendahuluan}

Sejak tahun 2014, pemerintah mulai menggalakan transformasi sektor publik menjadi berorientasi pada pelayanan masyarakat (public service) sehingga kinerja menjadi salah satu kualifikasi yang diutamakan (Liah, 2016). Pemerintah menyusun strategi meningkatkan anggaran sebesar 38.1\% dalam penyusunan RUU APBN 2019 sebagai usaha meningkatkan kualitas pembangunan sumber daya manusia. BPJS Ketenagakerjaan merupakan salah satu sektor penggerak pemerintah dalam bidang kesejahteraan sosial yang menjunjung tinggi pelayanan. Perusahaan ini mendukung budaya organisasi “ekselen" yang ditunjukan dengan perilaku kinerja tinggi.

Kinerja berperan sangat penting dalam memberikan gambaran mengenai kualitas organisasi (Ramli, 2019) dan hasil kerja sumber daya manusia di perusahaan terhadap deskripsi pekerjaan yang diberikan (Zainal, Ramly, Mutis, \& Arafah, 2019) dengan asumsi bahwa kinerja pegawai yang maksimal sejalan dengan peningkatan kinerja perusahaan (Apalia, 2017). Penelitian yang dilakukan (Wijaya \& Susanty, 2017) pada instansi pemerintah menunjukan bahwa lingkungan kerja yang baik mendukung peningkatan kemampuan dan loyalitas kepada perusahaan, kemudian memberikan pengaruh positif terhadap kinerja pegawai. Faktor lingkungan kerja adalah kunci dari peningkatan kinerja pegawai. Dibuktikan oleh penelitian (Yudiningsih, Yudiaatmaja, \& Yulianthini, 2016).

Berdasarkan hasil studi materi dari perusahaan dan wawancara, disampaikan bahwa adanya ketidakkonsistenan dalam memberi skor pada penilaian kinerja, kurang memahami sistem, tujuan penilaian tidak sesuai dengan tujuan perusahaan atau KPI yang digunakan kurang mencerminkan strategi perusahaan, poin penilaian antar wilayah dapat berbeda-beda dan adanya kebijakan penambahan nilai pada karyawan yang mengerjakan tugas diluar tanggung jawabnya (double job). Selain itu, perusahaan menggunakan tolak ukur New Performance Management untuk menilai kinerja perusahaan. Hasil wawancara menghasilkan temuan bahwa BPJS Ketenagakerjaan tidak memenuhi target realisasi sebesar 4\% pada periode 2018-2019 dan tidak memenuhi target absensi sebesar $0 \%$.

Berdasarkan (Yulianti, Sjahruddin, \& Tahir, 2017) menyatakan bahwa selain menentukan target kinerja yang akan dicapai, perusahaan memiliki kewajiban untuk mempertahankan kinerja pegawai, salah satunya dengan menyediakan lingkungan kerja yang kondusif. Lingkungan kerja yang baik memberikan dorongan motivasi pegawai, perilaku serta kepuasan kerja (Nzewi \& Hope 2018). Lingkungan kerja meliputi seluruh aspek yang mempengaruhi aktifitas pegawai di tempat kerja (Virgana, 2020). Menurut (Sitepu, Delimunte \& Sembiring, 2020), lingkungan kerja menjadi faktor peningkatan kinerja pegawai terbagi menjadi dua yaitu, fisik dan non fisik. Lingkungan kerja fisik berhubungan dengan sesuatu yang dapat dirasakan secara nyata, langsung maupun tidak langsung (Sedarmayanti, 2018). Lingkungan kerja fisik dapat dinilai berdasarkan indikator penataan cahaya, udara, kebisingan, temperatur dan tata ruang kerja (Omari \& Haneen, 2017). Lingkungan non fisik adalah suatu suasana di tempat kerja yang berhubungan dengan keadaan sosial atau interaksi antar rekan kerja (Indiyati et al., 
2018). Lingkungan non fisik berhubungan dengan kondisi psikologis. Lingkungan kerja bersifat penting dalam menentukan suasana yang nyaman dalam bekerja (Virgana, 2020).

Berdasarkan hasil kuisioner dan wawancara, lingkungan kerja di kantor dinilai kurang memuaskan berdasarkan indikator sirkulasi udara, kesediaan oksigen, tata ruang yang penuh dan adanya konflik yang ditandai dari kurangnya koordinasi antar pegawai dan kepada atasan. Lingkungan kerja fisik dan non fisik berpengaruh terhadap kinerja pegawai, berdasarkan hasil penelitian terdahulu oleh (Putri, Ekowati, Supriyanto, \& Mukaffi, 2019), dan (Djuremi, Hasiholan, \& Minarsih, 2016). Penelitian sebelumnya menggunakan analisis regresi linear berganda, sementara penelitian ini dilaksanakan menggunakan analisis jalur untuk mengetahui besarnya pengaruh langsung dan tidak langsung dari variabel yang diteliti serta mencari tahu adanya variabel-variabel yang dapat menjadi intervening untuk membentuk saran peningkatan kinerja. Peneliti menilai semakin berkembangnya ilmu mengenai faktor-faktor yang mempengaruhi kinerja pegawai sehingga perlu mencari tahu adanya keterikatan.

Berdasarkan latar belakang yang telah dijabarkan maka penelitian ini bertujuan untuk menentukan pengaruh lingkungan kerja fisik (X1) dan lingkungan kerja non fisik (X2) positif dan signifikan terhadap kinerja pegawai (Y) secara simultan. Pengaruh lingkungan kerja (X1) berpengaruh positif dan signifikan terhadap kinerja pegawai (Y) secara parsial. Pengaruh lingkungan kerja non fisik (X2) berpengaruh positif dan signifikan terhadap kinerja pegawai (Y) secara parsial.

\section{Metode Penelitian}

Metode analisis yang digunakan adalah kuantitatif. Teknik pengumpulan data menggunakan studi kepustakaan, observasi, wawancara dan survey dengan 25 butir pertanyaan yang diklasifikasikan dalam 5 skala likert. Metode analisis yang digunakan adalah kuantitatif deskriptif. Data diproses menggunakan metode analisis jalur (path analysis) dan uji hipotesis. Dalam analisis jalur perlu melakukan uji asumsi klasik untuk melihat pola model regresi dari variabel. Maka dari itu, pengolahan data pada penelitian ini meliputi uji reabilitas dan uji validitas, pengubahan skala ordinal menjadi interval menggunakan Method of Succesive Interval (MSI), dan uji asumsi klasik.

Tabel 1

Hasil Uji Asumsi Klasik

\begin{tabular}{lccc}
\hline \multicolumn{1}{c}{ Jenis Uji } & Syarat & Hasil & Kesimpulan \\
\hline Normalitas & $\begin{array}{c}\text { nilai asymp.sig (.sig) } \\
\text { > nilai Sig. } \\
\text { (Indrawati, 2015). }\end{array}$ & $0,2>0,05$ & Distribusi normal \\
\hline Multikolinier & $\begin{array}{l}\text { VIF }<10 \\
\text { (Indrawati, 2015). }\end{array}$ & $1,4<10$ & $\begin{array}{c}\text { Variabel independen } \\
\text { tidak terikat }\end{array}$ \\
\hline Heteroskedastisitas & $\begin{array}{c}\text { Tidak Ada Pola } \\
\text { Terpusat } \\
\text { (Indrawati, 2015). }\end{array}$ & Pola tersebar & $\begin{array}{c}\text { Ada ketidaksamaan } \\
\text { variabel residual }\end{array}$ \\
\hline Linearitas & Deviation from & $\mathrm{X} 1(0,275)>0,05$ & Linear \\
\hline
\end{tabular}




\begin{tabular}{lccc}
\hline \multicolumn{1}{c}{ Jenis Uji } & Syarat & Hasil & Kesimpulan \\
\hline & Linearity & X2 $(0,074)>0,05$ & \\
\hline Ketepatan & Standar Sig. & & Linear \\
Prediktor & Variabel $>$ Standar & X1 $(4,559)>3,873$ & \\
& Error Of The & X2(4,559) & \\
& Estimate & X3(5,554) & \\
& (Indrawati, 2015) & $>3,873$ & \\
\hline Autokorelasi & $-2<$ Nilai DW $<2$ & $-2<1,738<2$ & Tidak ada keterkaitan \\
& (Indrawati, 2015) & & antar variabel residual \\
\hline
\end{tabular}

Sumber: Hasil olahan peneliti

Kesimpulan berdasarkan tabel 1 uji asumsi klasik variabel memenuhi semua syarat sehingga variabel yang diteliti layak untuk uji analisis jalur.

\section{Hasil dan Pembahasan}

1. Analisis Deskriptif

Lingkungan kerja fisik sebesar 84,9\%, berada dalam kategori "sangat baik", artinya indikator seperti pencahayaan dalam ruang kerja, sirkulasi udara, tingkat kebisingan, luar dan tata ruang serta sarana dinilai memuaskan dan menunjang pekerjaan. Menurut (Cahyani, 2015) tingkat kenyamanan dalam lingkungan kerja mempengaruhi peningkatan kinerja pegawai.

Lingkungan kerja non fisik sebesar $82,4 \%$ berada dalam kategori "baik", artinya antar pegawai dapat bekerja sama dengan ideal, konflik yang berlangsung dihadapi secara profesional dan kepemimpinan dinilai berjalan dengan baik. Terciptanya lingkungan kerja non fisik yang ideal tercermin dari hubungan harmonis antar rekan kerja dan tidak adanya perselisihan diantara sesama rekan sekerja (Simamora, Hamid, \& Prasetya, 2016).

Kinerja karyawan sebesar $83.09 \%$ berada dalam kategori kondisi "sangat memuaskan", artinya pegawai mampu memenuhi indikator kualitas hasil kerja yaitu, ketelitian, kerapihan dan ketepatan target kerja, penyelesaian target kerja, kecepatan dan pembagian waktu secara baik, tingkat kehadiran yang tinggi, pemahaman dalam bekerja secara mandiri.

2. Analisis Jalur

Tabel 2

Hasil Analisis Jalur

\begin{tabular}{|c|c|c|c|c|}
\hline Variabel & $\begin{array}{l}\text { Koef. } \\
\text { Beta }\end{array}$ & $\begin{array}{l}\text { Pengaruh } \\
\text { Langsung }\end{array}$ & $\begin{array}{l}\text { Pengaruh Tidak } \\
\text { Langsung }\end{array}$ & $\begin{array}{c}\text { Total } \\
\text { Pengaruh }\end{array}$ \\
\hline & & & $\mathrm{X} 1$ & \\
\hline $\mathrm{X} 1$ & 0,589 & $35,7 \%$ & $19,3 \%$ & $55 \%$ \\
\hline $\mathrm{X} 2$ & 0.323 & $10,4 \%$ & $19,3 \%$ & $29,7 \%$ \\
\hline
\end{tabular}


Tabel 2 menunjukkan perhitungan analisis jalur. Kemudian disimpulkan lingkungan kerja fisik dan lingkungan kerja non fisik berpengaruh secara simultan terhadap kinerja pegawai bernilai $66,8 \%$. Pengaruh secara parsial terhadap kinerja, lingkungan kerja fisik bernilai 58,8\% serta lingkungan kerja non fisik bernilai 32,2\%. Total pengaruh lingkungan kerja fisik pegawai pada kinerja pegawai bernilai $55 \%$. Total pengaruh dari lingkungan kerja non fisik pada kinerja pegawai bernilai 29,7\%. Lingkungan kerja fisik memberikan pengaruh lebih besar, artinya sangat kuat untuk menjelaskan pengaruh yang terjadi pada kinerja pegawai (Fachreza \& Abd Majid, 2018).

Variabel residu merupakan variabel yang tidak diteliti, namun memberikan pengaruh terhadap variabel dependen. Dalam penelitian ini, variabel residu menunjukkan nilai 33,2\%. Berdasarkan penelitian terdahulu, variabel motivasi (Dimulyo, Sularso, \& Handriyono, 2018), kepemimpinan (Candrianto \& Gusti, 2020), kepuasan kerja pegawai (Pawirosumarto, Sarjana, \& Gunawan, 2017), dan pelatihan (Virgana, 2020) merupakan variabel yang dapat berpengaruh secara signifikan terhadap kinerja pegawai.

3. Pengujian Hipotesis

\begin{tabular}{ccccc}
\multicolumn{5}{c}{ Tabel 3 } \\
Uji F & & \\
\hline $\mathbf{R}^{2}$ & $\begin{array}{c}\text { Nilai F } \\
\text { Hitung }\end{array}$ & $\begin{array}{c}\text { Nilai F } \\
\text { Tabel }\end{array}$ & Sig & Probabilitas \\
\hline 0,668 & 33.181 & 3.28 & 0.00 & 0.05 \\
\hline
\end{tabular}

Sumber: Hasil olahan peneliti

Dapat disimpulkan dari tabel 3 Uji F, dengan signifikasi 0.00 dan Ftabel $3.28<$ Fhitung 33.181, artinya lingkungan kerja fisik dan lingkungan kerja non fisik berpengaruh terhadap kinerja pegawai secara simultan. Hasil penelitian menunjukkan lingkungan kerja siginifikan mempengaruhi kinerja pegawai (Hidayati, Perizade, \& Widiyanti, 2019).

Tabel 4

Uji T Lingkungan Kerja Fisik

\begin{tabular}{ccccc}
\hline Koef. & $\begin{array}{c}\text { Nilai T } \\
\text { Hitung }\end{array}$ & $\begin{array}{c}\text { Nilai T } \\
\text { Tabel }\end{array}$ & Sig & Probabilitas \\
\hline 0,588 & 5.020 & 2.0369 & 0.000 & 0,05 \\
\hline
\end{tabular}

Sumber: Hasil olahan peneliti

Dapat disimpulkan dari tabel 4 Uji T lingkungan kerja fisik, nilai signifikansi 0.00 dan $\mathrm{T}$ tabel 2.0369 < Thitung 5.020, artinya lingkungan kerja fisik mempengaruhi kinerja pegawai secara parsial. Menurut (Omari, 2017), lingkungan kerja fisik merupakan faktor yang kritikal dalam peningkatan kinerja pegawai. 
Penelitian (Nzewi \& Hope 2018) membuktikan pengaruh lingkungan kerja fisik pada kinerja pegawai sejalan dengan penelitian.

\section{Tabel 5}

Uji T Lingkungan Kerja Non Fisik

\begin{tabular}{ccccc}
\hline Koef. & $\begin{array}{c}\text { Nilai T } \\
\text { Hitung }\end{array}$ & $\begin{array}{c}\text { Nilai T } \\
\text { Tabel }\end{array}$ & Sig & Probabilitas \\
\hline 0,332 & 2.705 & 2.0369 & 0.01 & 0,05 \\
\hline
\end{tabular}

Sumber: Hasil olahan peneliti

Dapat disimpulkan dari tabel 4 uji $\mathrm{T}$ lingkungan kerja non fisik nilai signifikansi 0.00 dan Ttabel 2.0369 < Thitung 2.70, artinya lingkungan kerja non fisik mempengaruhi kinerja pegawai secara parsial. Penelitian sebelumnya oleh (Liestiani, Perizade \& Agustina Hanafi, 2019) menunjukkan bahwa lingkungan kerja non fisik memberikan pengaruh terhadap kinerja pegawai. Hubungan harmonis antar pegawai berbanding lurus dengan peningkatan produktivitas kerja (Yuliantari \& Prasasti, 2020). Lingkungan kerja non fisik memberikan efek perubahan psikologis pegawai sehingga perlunya kondisi kerja yang nyaman agar memberikan motivasi dalam melaksanakan pekerjaan mereka (Wijaya \& Susanty, 2017).

\section{Kesimpulan}

Berdasarkan hasil pembahasan maka dapat diperoleh kesimpulan bahwa lingkungan kerja fisik berada pada klasifikasi tingkat "sangat baik". Berdasarkan indikator variabel penelitian, fasilitas perusahaan dinilai secara keseluruhan telah mendukung kinerja pegawai. Lingkungan kerja non fisik berada pada klasifikasi tingkat "baik". Berdasarkan indikator variabel penelitian, kondisi sosial dinilai positif dan ramah secara keseluruhan cenderung mendukung kinerja pegawai. Kinerja pegawai berada pada klasifikasi "sangat memuaskan". Berdasarkan indikator penelitian, pegawai dinilai mampu memenuhi kriteria penilaian kinerja. Lingkungan kerja fisik dan lingkungan kerja non fisik mempengaruhi kinerja karyawan sebesar 66,8\% secara simultan. Pengaruh langsung lingkungan kerja fisik sebesar $55 \%$ pada perubahan tingkat kinerja karyawan. Pengaruh langsung lingkungan kerja non fisik sebesar 29,7\% pada perubahan tingkat kinerja karyawan. Variabel residu sebesar 33,2\%, artinya ditemukan faktor-faktor lain yang berhubungan dengan lingkungan kerja seperti motivasi, tingkat kedisiplinan, sanksi, gaya kepemimpinan, dan kompensasi. Maka dari itu diharapkan peneliti selanjutnya dapat memuat variabel tersebut serta dapat mengimplementasikan pada industri atau sektor lain dengan responden yang lebih banyak. Setiap perusahaan dapat memiliki lingkungan dan budaya yang berbeda, sehingga akan menghasilkan keobjektivan penelitian yang dilakukan. 


\section{BIBLIOGRAFI}

Apalia, E. A. (2017). Effects Of Discipline Management On Employee Performance In An Organization: The Case Of County Education Office Human Resource Department, Turkana County. International Academic Journal Of Human Resource And Business Administration, 2(3), 1-18. Google Scholar

Cahyani, Firda Anggun. (2015). Pengaruh Disiplin Dan Lingkungan Kerja Terhadap Kinerja Dosen Fakultas Ekonomi Dan Bisnis Universitas Muhammadiyah Surakarta. Universitas Muhammadiyah Surakarta. Google Scholar

Dimulyo, Ultafakoh Paranitha, Sularso, Raden Andi, \& Handriyono, Handriyono. (2018). The Influence Of Organizational Culture And Work Discipline On Motivation And Performance Of Banking Employees. Google Scholar

Djuremi, Djuremi, Hasiholan, Leonardo Budi, \& Minarsih, Maria Magdalena. (2016). Pengaruh Lingkungan Kerja, Budaya Organisasi, Dan Kepemimpinan Terhadap Kinerja Pegawai Pada Dinas Pasar Kota Semarang. Journal Of Management, 2(2). Google Scholar

Fachreza, Said Musnadi, \& Abd Majid, M. Shabri. (2018). Pengaruh Motivasi Kerja, Lingkungan Kerja, Dan Budaya Organisasi Terhadap Kinerja Karyawan Dan Dampaknya Pada Kinerja Bank Aceh Syariah Di Kota Banda Aceh. Jurnal Magister Manajemen Issn, 2302, 199. Google Scholar

Hersona, Sonny, \& Sidharta, Iwan. (2017). Influence Of Leadership Function, Motivation And Work Discipline On Employees'performance. Jurnal Aplikasi Manajemen, 15(3), 528-537. Google Scholar

Hidayati, Siti Karlina, Perizade, Badia, \& Widiyanti, Marlina. (2019). Effect Of Work Discipline And Work Environment To Performance Of Employees. International Journal Of Scientific And Research Publications, 9(12), 391-398. Google Scholar

Indiyati, Dian, Kurniawan, Asep, \& Choirunnisa, Medina. (2018). Lingkungan Kerja Dan Motivasi Kerja Pada Perusahaan Manufaktur Untuk Mendukung Pariwisata Indonesia. Jurnal Pariwisata, 5(3), 203-212. Google Scholar

Indrawati, Ph D. (2015). Metode Penelitian Manajemen Dan Bisnis Konvergensi Teknologi Komunikasi Dan Informasi. Bandung: Pt Refika Aditama. Google Scholar

Liah, Kukuh Wijaksono. (2016). Pengaruh Lingkungan Kerja Terhadap Kinerja Pegawai Di Kantor Kecamatan Balikpapan Utara Kota Balikpapan. Google Scholar

Liestiani, Nurul Laras, Perizade, Badia, \& Agustina Hanafi, Zunaidah. (2019). The Effect Of Work Discipline And Work Environment On The Performance Of Al 
Hudori Cooperative Of Palembang Employees. Journal Of Economics And Business, 2(1), 61-72. Google Scholar

Nzewi, Hope N., Augustine, A., Mohammed, I., \& Godson, O. (2018). Physical Work Environment And Employee Performance In Selected Brewing Firms In Anambra State, Nigeria. Journal Of Good Governance And Sustainable Development In Africa, 4(2), 131-145. Google Scholar

Omari, Et Al; (2017). The Influence Of Work Environment On Job Performance: A Case Study Of Engineering Company In Jordan. International Journal Of Applied Engineering Research, 12(24), 15544-15550. Google Scholar

Pawirosumarto, Suharno, Sarjana, Purwanto Katijan, \& Gunawan, Rachmad. (2017). The Effect Of Work Environment, Leadership Style, And Organizational Culture Towards Job Satisfaction And Its Implication Towards Employee Performance In Parador Hotels And Resorts, Indonesia. International Journal Of Law And Management. Google Scholar

Putri, Elok Mahmud, Ekowati, Vivin Maharani, Supriyanto, Achmad Sani, \& Mukaffi, Zaim. (2019). The Effect Of Work Environment On Employee Performance Through Work Discipline. International Journal Of Research-Granthaalayah, 7(4), 132-140. Google Scholar

Ramli, Abdul Haeba. (2019). Work Environment, Job Satisfaction And Employee Performance In Health Services. Business And Entrepreneurial Review, 19(1), 2942. Google Scholar

Samsuddin, Harun. (2018). Kinerja Karyawan: Tinjauan Dari Dimensi Gaya Kepemimpinan, Budaya Organisasi Dan Komitmen Organisasi. Edisi Pertama. Sidoarjo: Indomedia Pustaka. Google Scholar

Sedarmayanti, H. J. (2018). Tata Kerja Dan Produktivitas Kerja. Google Scholar

Simamora, Hendra Winarta, Hamid, Djamhur, \& Prasetya, Arik. (2016). Pengaruh Lingkungan Kerja Fisik Dan Non Fisik Terhadap Motivasi Kerja Karyawan (Studi Pada Karyawan Hotel Atria \& Konferensi Malang). Jurnal Administrasi Bisnis, 31(1), 158-166. Google Scholar

Virgana, Virgana. (2020). The Effect Of Job Performance Through Organizational Culture, Work Environment, Personality, And Motivation. Jurnal Manajemen Dan Kewirausahaan (Journal Of Management And Entrepreneurship), 22(2), 87-98. Google Scholar

Wijaya, Hendry, \& Susanty, Emi. (2017). Pengaruh Lingkungan Kerja Terhadap Kinerja Pegawai Pada Instansi Pemerintah Daerah Kabupaten Musi Banyuasin (Studi Kasus Dinas Pertambangan Dan Energi Kabupaten Musi Banyuasin). Jurnal Ecoment Global: Kajian Bisnis Dan Manajemen, 2(1), 40-50. Google Scholar 
Pengaruh Lingkungan Kerja terhadap Kinerja Pegawai pada Badan Penyelenggara Jaminan Sosial Ketenagakerjaan Jawa Barat

Yudiningsih, Ni Made Diah, Yudiaatmaja, Fridayana, \& Yulianthini, Ni Nyoman. (2016). Pengaruh Lingkungan Kerja Dan Disiplin Kerja Terhadap Kinerja Pegawai. E-Journal Bisma Universitas Pendidikan Ganesha. Singaraja: Universitas Pendidikan Ganesha. Google Scholar

Yulianti, Luli, Sjahruddin, Herman, \& Tahir, Bungatang. (2017). Implementasi Customer Relationship Management (Crm) Terhadap Kepuasan Dan Loyalitas Pelanggan Pengguna Smartphone Android Merek Samsung. Google Scholar

Zainal, Veithzal Rivai, Ramly, H. Mansyur, Mutis, Thoby, \& Arafah, Willy. (2019). Manajemen Sumber Daya Manusia Untuk Perusahaan Dari Teori Ke Praktik. Google Scholar

\section{Copyright holder:}

Syifa’ Pri Widyastuti, Dian Indiyati (2021)

First publication right:

Syntax Literate: Jurnal Ilmiah Indonesia

This article is licensed under:

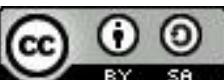

